\title{
Fundamental Toxicology
}

\author{
J.H. Duffus and H.G.J. Worth \\ The Royal Society of Chemistry, 2006 \\ ISBN 0854046143
}

Fundamental Toxicology is a concise and comprehensive review of toxicology. It is based on the highly successful Fundamental Toxicology for Chemists (J.H. Duffus and H.G.J. Worth, The RSC, 1996) and has been enriched and expanded. Every chapter in this new edition has been revised and updated, and four new chapters have been added.

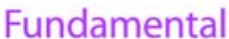

\section{TOXICOLOGY}

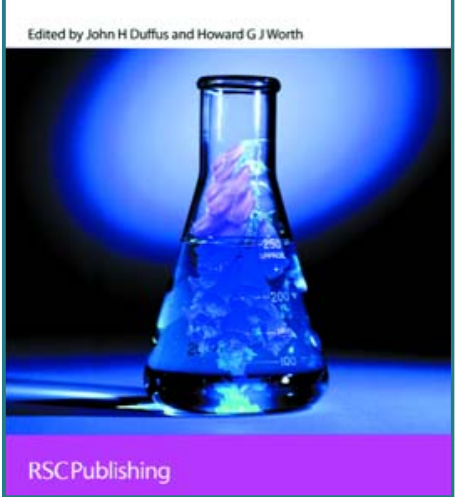

With contributions from internationally recognized experts in their field, this broad-based introduction to the topic covers both wellestablished and rapidly developing areas of toxicology, such as toxicogenomics, reproductive toxicology, behavioral toxicology and ecotoxicology.

Fundamental Toxicology is ideal for students and includes extensive pedagogical features, such as an extensive glossary, a bibliography after each chapter, and recommended further reading. It is also designed for teachers and lecturers, especially those who may be teaching toxicology for the first time. Included is a suggested curriculum for using the text to teach toxicology to students from various scientific disciplines. Professionals working in toxicology and related fields will find this an invaluable guide.

This book represents the outcome of the IUPAC project of the same title. The textbook also complement the editors presentations on "Essential Toxicology." which are educational resources available on the IUPAC website <www.iupac.org/publications/cd/essential _toxicology $>$.

\section{Diii www.iupac.org/publications/books/author/duffus06.html}

Definitions of terms used in toxicology and in toxicokinetics are regularly being evaluated and updated by IUPAC task groups coordinated by the Subcommittee on Toxicology and Risk Assessment. See provisional recommendations currently under public review or the subcommittee Web page for more information <wWw.iupac.org/divisions/VII/VII.C.2>.

\section{Macromolecular Symposia-recent volumes}

Fillers, Filled Polymers, and Polymer Blends

P. Dubois, G. Groeninckx, R. Jerome,

R. Legras (editors)

Macromolecular Symposia, Vol. 233

Wiley-VCH, 2006, pp. 1-236

About 300 scientists from 35 countries attended this first joint meeting between the 8th European Symposium on Polymer Blends and Eurofillers 2005, held in Bruges, Belgium, from 9-12 May 2005. The conference featured 16 plenary/keynote lectures, 44 oral communications, and more than 200 poster presentations. This volume of Macromolecular Symposia covers most of the plenary and oral contributions presented at the meeting.

"Materials Design, Performance and Problem Solving" was the general theme of this meeting, which was meant to stimulate dialogue among specialists in complementary fields, such as physics, chemistry, and engineering, who have expertise in both organic and inorganic materials. The topics covered during the meeting included:

In the field of polymer blends:

- innovations in generation and control of phase morphology, including theoretical approaches and numerical simulations

- reactive processing, including reactive compatibilization, dynamic crosslinking, and polymer chemistry in the melt

- control, characterization, and modeling of interfaces and interphases

-structure-mechanical performance relationships -specific polymer blends (including recycling) and their applications

In the field of fillers and filled polymers

- preparation and characterization of (nano) fillers of all shapes and functions

- formulations of (nano)fillers with polymers, including nanocomposites, natural fiber composites, and organicinorganic hybrid materials

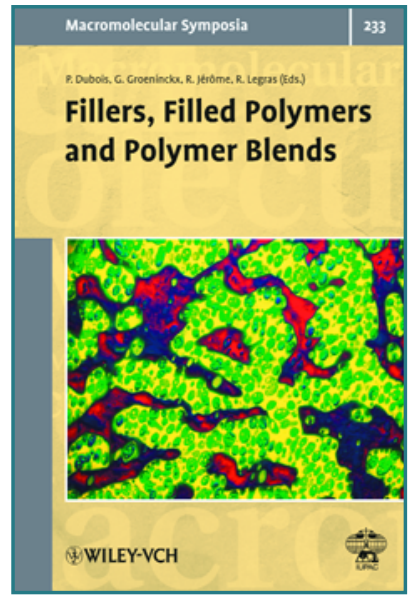

